\title{
Impacted dental bridge in the esophagus following general anesthesia: A case report
}

\author{
Jeong-Heon Park, Jaegyok Song, Chaemin Cho \\ Department of Anesthesiology and Pain Medicine, Dankook University College of Medicine, Cheonan, Korea
}

\begin{abstract}
A dental bridge impacted in the esophagus of a 43-year-old man was successfully removed using endoscopy, without any further complications. It is of utmost importance that the medical staff carefully assess the patient's dental condition, provide clear documentation, and notify the patient appropriately to prevent dental prosthesis-related complications and claims. Anesthesiologists also need to be more cautious in the perioperative period, even after extubation, because this complication may not be completely avoidable.
\end{abstract}

Keywords: Dental Bridge; Esophagus; Foreign Bodies; Gastroscopy.

This is an Open Access article distributed under the terms of the Creative Commons Attribution Non-Commercial License (http://creativecommons.org/licenses/by-nc/4.0/) which permits unrestricted non-commercial use, distribution, and reproduction in any medium, provided the original work is properly cited.

\section{INTRODUCTION}

Perioperative dental injury and aspiration of dental prosthesis or tooth are rare complications that could induce catastrophic consequences, such as esophageal perforation and mediastinitis [1-4]. Ham et al. [5] reported that the incidence of perioperative dental injury was $0.03 \%$. To prevent dental injury during anesthesia, preoperative assessment and precautions need to be undertaken; however, this is not a completely preventable complication, and anesthesiologists need to assess the dental condition preoperatively and clearly document the patient's dental condition [6]. Early diagnosis and immediate treatment, including surgical removal of the impacted dental prosthesis in the esophagus, are crucial to prevent these complications [7]. We report a case of esophageal impaction of a dental bridge with a review of the literature. The patient provided informed consent for publication as a case report.

\section{CASE}

A 43-year-old male patient (ASA class I, weight 65 $\mathrm{kg}$, height $173 \mathrm{~cm}$ ) with right-side ankle fracture was scheduled for closed reduction and internal fixation. The medical history was unremarkable, with no history of surgery. Preoperative evaluations including laboratory tests, electrocardiography, and chest radiography revealed normal results. The patient denied the presence of any loose teeth or presence of dental prosthesis on questioning.

After the institution of standard monitors and pre-oxygenation, general anesthesia was induced with intravenous injection of $60 \mathrm{mg}$ lidocaine, $100 \mu \mathrm{g}$ fentanyl, $100 \mathrm{mg}$ propofol, and $40 \mathrm{mg}$ rocuronium. Following mask ventilation for $3 \mathrm{~min}$ with $100 \%$ oxygen and $7 \mathrm{vol} \%$ desflurane, the patient was intubated with conventional direct laryngoscopy, and a bite-block was used to protect the endotracheal tube. The induced general anesthesia

Received: March 11, 2019 - Revised: April 2, 2019 - Accepted: April 3, 2019

Corresponding Author: Jaegyok Song, Department of Anesthesiology and Pain Medicine, Dankook University College of Medicine, Dankook University, Dadae-ro 119, Cheonan 31116, Korea

Tel: +82-41-550-6819 Fax: +82-41-551-9330 E-mail: drjack@nate.com

Copyright(c) 2019 Journal of Dental Anesthesia and Pain Medicine 


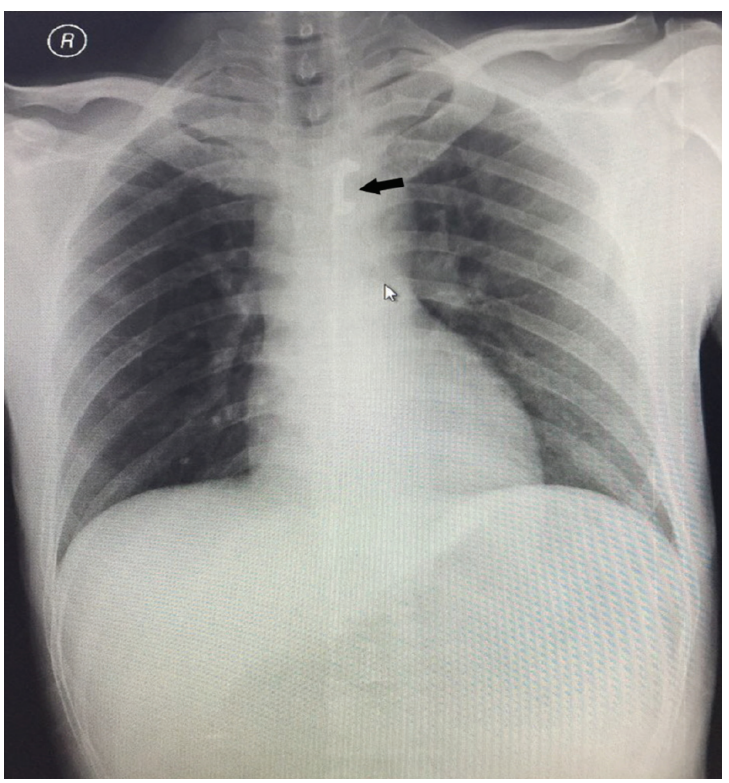

Fig. 1. Chest radiograph showing impacted dental bridge (black arrow) in the mid esophagus region.

was maintained with $7-8$ vol $\%$ desflurane, and the surgery was performed successfully in an operating time of $2 \mathrm{~h}$ 45 min. Residual muscle relaxation was reversed with atropine and neostigmine after procedure completion. The patient successfully recovered without any complications and was extubated. No dental damage was noticed when the oral secretions were cleared with a suction apparatus, before and after extubation. The patient was transferred to the post-anesthesia care unit (PACU), and the patient complained of chest discomfort $20 \mathrm{~min}$ later and could not feel his upper incisors. An oral examination revealed that the upper incisors were missing, and we assumed that the patient had lost the dental bridge. Chest radiography was performed immediately, and a radiopaque shadow of the dental bridge in the esophagus was observed (Fig. 1). The patient was transferred to the endoscopy room to remove the foreign object. During the pre-procedure check in the endoscopy room, the nurse again asked the patient whether he had any other dental prostheses, and he said that he had removed his dentures before the esophagoscopy. The impacted dental bridge was successfully removed using esophago-gastroscopy, without any complications (Fig 2). The patient was discharged 6 days after surgery with no complications.

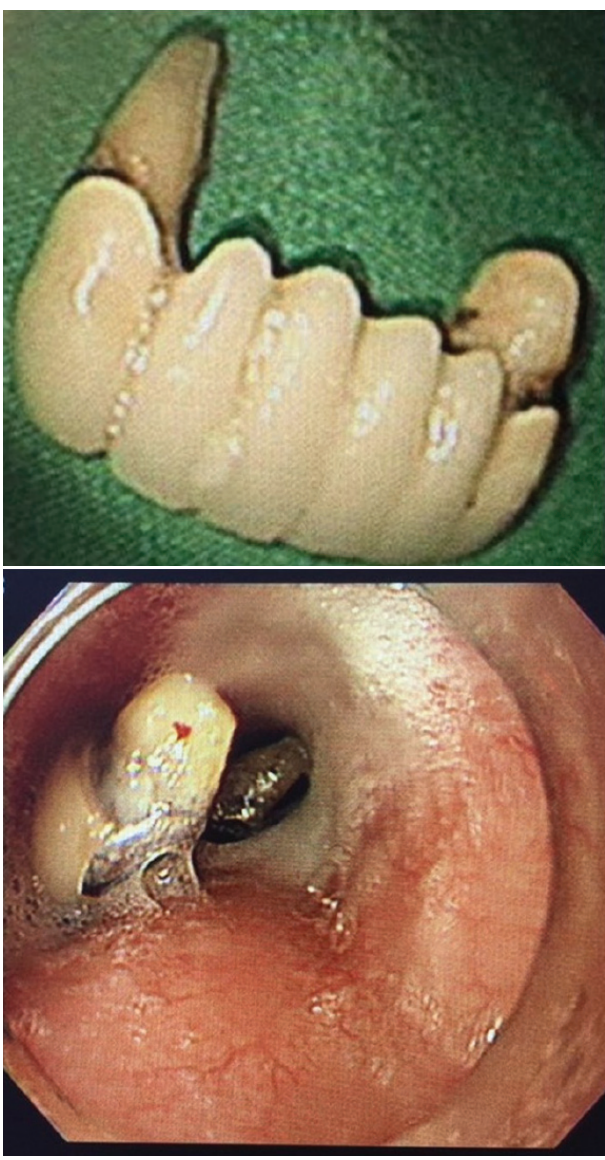

Fig. 2. Removed dental bridge prosthesis and endoscopic view of the dental bridge in the esophagus.

\section{DISCUSSION}

Dental injury during perioperative period is one of the most common incidents associated with general anesthesia [6,8]. Giraudon et al. [8] reported that amongst 1514 claims related to anesthesia, 592 (39.2\%) were classified as dental injury, and that the prevalence of tooth injury and dental bridge injury was $65.2 \%$ and $12.8 \%$, respectively. The preoperative assessment of the patient's dental condition and clear documentation by the anesthesiologist are very important to prevent dental injury and related claims $[6,8]$. Preoperative dental treatment should be considered, and notifying the patient about the dental condition and possibility of dental damage during anesthesia is important [6].

In this case, the patient had an upper partial denture 
and dental bridge, but this information was not assessed properly because the patient denied it. There were several instances to record this information. First, when the patient was admitted and asked by a nurse if he had any dental problems or artificial dental prosthesis, the patient responded in negative. Second, a nurse prepared the patient before sending him to the operating room and asked him to remove all accessories including dentures but the patient did not. Third, in the operating room, the anesthetic nurse again asked the patient for the presence of any artificial dental prosthesis, and he again responded in negative. Lastly, the anesthetic resident checked his dental condition and asked the same question again, and the patient again denied it. The resident failed to notice the upper incisors dental bridge and lower dentures, and they appeared intact. We did not notice that the patient had a dental bridge and used an oral bite-block to prevent chewing of the endotracheal tube that caused the prosthesis to dislodge. Therefore, anesthesiologists must check the dental status precisely not only by asking the patient verbally but also by opening the patient's mouth to observe and palpate, if needed, to confirm the dental status. After the assessment, proper precautions needed to be undertaken to prevent dental injury and related complications.

Impaction of dental prosthesis in the esophagus or trachea is a rare complication [1,7]. The incidence of a foreign body impaction of dental origin is not well known. Abdullah et al. [9] reported that the incidence of dental foreign body in the esophagus was $11.5 \%$. Dental prostheses usually have sharp metal parts, and can induce serious complications including esophageal perforation and mediastinitis [4]. Mediastinitis induced by esophageal perforation is a serious complication and can prove fatal in $20 \%$ cases [10]. Kim et al. [10] reported that 13 patients had esophageal perforation among 196 patients with foreign body in the esophagus. However, if the esophageal foreign body is treated within $24 \mathrm{~h}$, the risk of esophageal perforation can be significantly reduced.

The first choice of treatment for esophageal foreign body treatment is endoscopy [2,3]. However, it has been reported that approximately $2 \%$ patients experienced esophageal perforation after endoscopic foreign body removal [10]. If there is a risk of esophageal perforation because of sharp margins of the foreign body, surgical removal should be considered $[3,4,7]$.

In conclusion, an impacted dental bridge in the esophagus was successfully removed using endoscopy, without further complications. It is important that the medical staff carefully assess and clearly document the patient's dental condition and notify the patient to prevent dental prosthesis-related complications and claims. Anesthesiologists should be more cautious because this complication is not completely preventable.

\section{AUHOR OROLIS}

Jeong-Heon Park: https://orcid.org/0000-0003-3852-5390

Jaegyok Song: https://orcid.org/0000-0002-4727-6296

Chaemin Cho: https://orcid.org/0000-0003-4723-9353

ACKNOWLEDGEMENTS: This article was financially supported by Dankook University, Cheonan, South Korea.

\section{REFERENCES}

1. Panigrahi B, Sahay N, Samaddar DP, Chatterjee A. Migrating foreign body in an adult bronchus: An aspirated denture. J Dent Anesth Pain Med 2018; 18: 267-70.

2. Wang C, Chen P. Removal of impacted esophageal foreign bodies with a dual-channel endoscope: 19 cases. Exp Ther Med 2013; 6: 233-5.

3. Gallas M, Blanco M, Martinez-Ares D, Rivo E, Garcia-Fontan E, Canizares M. Unnoticed swallowing of a unilateral removable partial denture. Gerodontology 2012; 29: e1198-200.

4. Tihan D, Trabulus D, Altunkaya A, Karaca S, Cihan A, Alis H. Esophageal perforation due to inadvertent swallowing of a dental prosthesis. Turk J Gastroenterol 2011; 22: 529-33. 
5. Ham SY, Kim J, Oh YJ, Lee B, Shin YS, Na S. Risk factors for peri-anaesthetic dental injury. Anaesthesia 2016; 71: $1070-6$.

6. Yasny JS. Perioperative dental considerations for the anesthesiologist. Anesth Analg 2009; 108: 1564-73.

7. Toshima T, Morita M, Sadanaga N, Yoshida R, Yoshinaga K, Saeki H, et al. Surgical removal of a denture with sharp clasps impacted in the cervicothoracic esophagus: report of three cases. Surg Today 2011; 41: 1275-9.

8. Giraudon A, de Saint Maurice G, Biais M, Benhamou D, Nouette-Gaulain K. Dental injury associated with anae- sthesia: An 8-year database analysis of 592 claims from a major French insurance company. Anaesth Crit Care Pain Med 2018; 37: 49-53.

9. Abdullah BJ, Teong LK, Mahadevan J, Jalaludin A. Dental prosthesis ingested and impacted in the esophagus and orolaryngopharynx. J Otolaryngol 1998; 27: 190-4.

10. Kim JE, Ryoo SM, Kim YJ, Lee JS, Ahn S, Seo DW, et al. Incidence and Clinical Features of Esophageal Perforation Caused by Ingested Foreign Body. Korean J Gastroenterol 2015; 66: 255-60. 